\title{
INTERGENERATIONAL RISK SHARING
}

\author{
Roger H. GORDON \\ University of Michigan, Ann Arbor, MI 48109, USA \\ National Bureau of Economic Research \\ Hal R. VARIAN* \\ University of Michigan, Ann Arbor, MI48109, USA
}

Received June 1987, revised version received September 1988

In this paper we examine government debt and tax-transfer policies that can improve the allocation of risk between generations. Markets cannot allocate risk efficiently between two generations whenever the two generations are not both alive prior to the occurrence of a stochastic event. This implics that government policics transferring risk between generations have the potential to create first-order welfare improvements. Our model provides a nonKeynesian justification for the debt-finance of wars and recessions, as well as an added rationale for Social Security type tax-transfer schemes which aid unlucky generations, e.g. the Depression generation, at the expense of luckier generations.

\section{Introduction}

It is well known that economic efficiency requires that any risk in the economy be shared among individuals in such a way that each individual charges the same risk premium for an additional share in each lottery. If such efficient risk sharing does not occur, then in principle contingent consumption can be reallocated so as to make everyone better off. For example, a number of authors have explored the implications of the fact that individuals cannot easily avoid bearing the risk of fluctuations in their own labor income. Given this observation, Varian (1980) and Eaton and Rosen (1980) have argued that a personal income tax may result in a more efficient allocation of risk in the economy. ${ }^{1}$ Even when fluctuations in labor income are shared by all workers, Merton (1984), Fischer (1982), and Enders and Lapan (1982) have argued that when there is no market in a security

\footnotetext{
*We would like to thank Stewart Myers, Maurice Obstfeld, Lawrence Summers, and participants of seminars at Michigan, Princeton, Harvard, Tel-Aviv, Jerusalem, Bonn, and the N.B.E.R., for helpful discussion and comments.

${ }^{1}$ Buchanan (1976) argued that this risk-sharing aspect of the personal tax may explain the strong political support for it.
} 
corresponding to aggregate labor income, then the government can still reallocate risk to non-workers through a labor income tax in a Paretoimproving way. ${ }^{2}$ Similarly, Aizenman (1981) argued that the government can beneficially offset domestic economic shocks through modification of the exchange rate when the international securities market fails to pool risks internationally.

In each of these cases, there exists the question of why there is no market in a particular lottery, and whether the reasons that prevented the market from pooling a lottery appropriately may also prevent the government from raising utility by doing so. For example, if there is no private market allowing diversification in the risk in an individual's labor income because the moral hazard costs of doing so outweigh the benefits, then the government, also facing these moral hazard costs, can do no better than the market. In contrast, if no private market exists because of adverse selection reasons, then the government will be able to avoid these problems by making participation in the risk-pooling scheme compulsory. Since it is normally unclear why a private market fails to exist in a particular lottery, it is also unclear whether there is any potential for fruitful government intervention.

Markets also do not appear able to pool lotteries faced by different nonoverlapping generations. However, here the reason why risk-sharing markets fail to exist seems clear. Later generations cannot participate in the securities market for lotteries which occur before they are born because they arc not alive ex ante to buy shares in these lotteries. An agent cannot profitably buy shares on behalf of later generations since there would be no legal mechanism to force these later generations to accept any losses, implying that the agent would have no incentive to pass on any gains. The problem is that later generations cannot precommit themselves to participate in a lottery even when they would gain in expected utility by doing so. By the time they can commit themselves, they know the outcome. These problems arise whenever two generations are not both active in the securities market before the outcome of a particular lottery is revealed, even if their lives do overlap at some point.

The government, however, could well have the power to commit later generations to share in the outcome of earlier lotteries. If so, there is the potential for Pareto-improving government policies which share the risk between different generations. In fact, some government policies do seem to have been used, whether consciously or otherwise, for just this purpose. For example, historically, debt has been issued to help finance unfavorable events, such as wars and recessions, and paid off only gradually over later generations. Diamond (1965) worked out in a very general setting just how

\footnotetext{
${ }^{2}$ While there may be no explicit mechanism available to trade risk in labor income, firms may be able to reallocate risk between workers and capital owners through implicit labor contracts, an idea explored by Azariadis (1975) and Baily (1974).
} 
debt issues result in a reallocation of wealth between generations. By the same argument, stochastic issues of debt result in a reallocation of risk between generations. A plausible argument might be made that the initial role of the U.S. Social Security program was to aid the generations who lost both financial wealth and labor income during the Great Depression.

The objective of this paper is to explore the characteristics of an optimal government risk-sharing scheme, assuming that the government has the power to precommit future generations. Since there is an arbitrarily large number of future generations to share in any particular lottery (e.g. today's recession), one might expect, by analogy with the diversification theorems in finance, that on efficiency grounds each generation ought to bear an arbitrarily small share in the outcome of any lottery. ${ }^{3}$ This argument is formalized in section 2 .

One problem with this argument is that the process by which random outcomes are shared with future generations is by adding to the capital stock when the outcome is favorable and consuming part of the capital stock when the outcome is unfavorable. Yet accounting explicitly for the economic effects of changing the capital stock makes the problem much more complicated. This complication is explored in section 3.

In these sections we assume that the government has the power to precommit future generations, and examine what kind of government behavior would lead to an efficiency gain. However, the government may not plausibly be able to precommit later generations, regardless of the ex post outcomes. While the risk-sharing policy raises the expected utility of future generations, based on the information available at the time of enactment of the policy, future generations may well find themselves worse off at birth than they would be if the policy could be repealed. In section 4 we explore several models of government behavior to forecast whether a given risksharing scheme would end up being repealed at a later date when some future generation, seeing past outcomes, finds the implications of the policy unfavorable for it. We argue here that the use of both debt and Social Security to transfer risk between generations could well be time-consistent.

While this paper provides an explanation for debt finance of wars and recessions, and one explanation for the enactment of Social Security, many other explanations are possible. In section 5, we briefly compare our explanation with some alternative explanations.

Throughout the above discussion, we ignore the possibility that the family can engage in similar risk-sharing schemes between different generations, eliminating the need for government intervention. In fact, one might reinterpret our results as describing optimal family behavior rather than optimal government behavior. In section 6 we briefly explore in what ways

\footnotetext{
${ }^{3}$ This intuition has been stated previously in Stiglitz (1983) and Gordon (1985).
} 
risk sharing through the family would face different problems than risk sharing through the government.

\section{Risk sharing between generations: Base case}

We begin by exploring risk sharing in a very simple two-period overlapping generations model. For simplicity, we assume there is no population growth ${ }^{4}$ and no technological change. Generations are therefore identical except for the period in which they are born. The generation born in period $t$, and its earnings, are denoted through the use of a subscript $t$.

Members of each generation are assumed to work only while they are young and to consume only while they are old. We assume they work a fixed amount while young, earning a non-stochastic wage, $w$. They save this labor income and earn a stochastic return, $e_{t}$, on it with mean zero and variance $s$, allowing them to consume $w+e_{t}$ when they are old..$^{5}$ Their utility depends solely on their consumption, which is stochastic. We assume, for simplicity, that their ex ante utility can be expressed as a function of their expected income and the variance of this income, and denote their utility by $U(w)-V(s) .^{6}$

The outcome of the stochastic event is revealed 'between periods'; that is, after the previous generation has died but before the next generation is born. For simplicity, we assume that each stochastic event is identically distributed and independent of all others. Because there are never two generations alive both before and after a stochastic event, there is no possibility of sharing risk between generations through the market. We assume, though, that risk is efficiently shared among members of each generation. Each individual therefore has expected utility of $U(w)-V(s)$. When it adds clarity, we include a subscript on the utility function indicating the generation number.

Since two generations are always alive simultaneously, however, the government can transfer income from one to the other, based on the outcome of past events, and thereby raise the expected utility of every generation. ${ }^{7}$ For example, if the government transfers $e_{t-1} / 2$ from the old to

\footnotetext{
${ }^{4}$ Green (1977) and Smith (1982) describe intergenerational risk-sharing models where the source of risk is random fluctuations in the birth rate, imposing risk on individuals through the resulting random fluctuations in wage rates and interest rates. Random population growth leads to quite different complications than arise when output is random. In this section, for example, we assume factor prices are unaffected by the capital-labor ratio, an assumption which would eliminate the effects of random population growth on welfare.

${ }^{5}$ This stochastic return represents the return on the 'market portfolio'. We assume for simplicity that the same random income $e_{t}$ is received independently of how much is saved from the previous period.

${ }^{6}$ Most of our results generalize easily to an expected utility model, though exposition is simpler in a mean-variance setting.

${ }^{7}$ The expected utility is computed as of the date of the enactment of the program, a point we will discuss further below.
} 
the young in each period $t$, then the young in period $t$ receive net income of $w+e_{t-1} / 2$. This income is saved, providing $w+e_{t-1} / 2+e_{t}$ the next period. Part of this is paid as a transfer to the next generation, however, leaving $w+\left(e_{t-1}+e_{t}\right) / 2$ for consumption. Expected utility of all but the initial generation $t$ would therefore be:

$$
U(w)-V\left(\operatorname{var}\left(\left[e_{t-1}+e_{t}\right] / 2\right)\right)=U(w)-V(s / 2) .
$$

Each lottery is shared between two generations, allowing a pooling of risks and an increase in expected utility. The first generation does even better since it shares in only one lottery. Its expected utility equals $U(w)-V\left(\operatorname{var}\left(e_{1} / 2\right)\right)=$ $U(w)-V(s / 4)$. Thus, this policy represents a Pareto improvement in expected utility - all generations can be expected to be made better off by this risksharing arrangement.

This tax-transfer scheme can easily be redesigned so as to share each lottery between $n$ generations. For example, the net transfer from old to young in period $t$ can be specified to be $\sum_{i=1}^{n-1}[(n-i) / n] e_{t-i}$. The consumption of generation $t$ would then equal $w+\sum_{i=0}^{n-1} e_{t-i} / n$. Its utility, expected as of the date of enactment of the policy, can be expressed as:

$$
U(w)-V\left(\operatorname{var}\left(\sum_{i=0}^{n-1} e_{t-i} / n\right)\right)=U(w)-V(s / n)
$$

Again the first $n-1$ generations would fare even better. As risk is shared among more generations - as $n$ becomes larger - the expected utility of each generation increases. As $n$ increases without bound, each generation's utility converges to $U(w)$ and the costs of bearing the collective risks drop to zero.

It is important to realize that the transfers are made only between the two generations that are alive contemporaneously. However, the magnitude of the transfer from generation $t-1$ to generation $t$ is a function of the random outcome of the lotteries of the $n-1$ earlier generations. Thus, in effect, risk is being shared among $n$ generations.

In this argument we described the government policy as a tax-transfer scheme. It could equivalently have been described as a particular stochastic government debt policy. If each lottery is to be shared equally between $n$ generations, then the government upon seeing the outcome $e_{t}$ can retire $\left[(n-1 / n] e_{t}\right.$ dollars of debt, funded by a tax on the old (those who received $e_{t}$ ), then reissue $e_{t} / n$ dollars of debt during each of the following $n-1$ periods, paying the proceeds of each debt issue to the old in that period. This policy 
results in the same redistribution of risk as the tax-transfer scheme described above. $^{8}$

Obviously, the above model is highly simplified. However, the conclusions are robust to many types of generalizations. The basic intuition being modeled is that each lottery ought to be shared relatively equally among all current and future individuals. What is social risk at any one date is idiosyncratic risk when pooled with the independent lotteries of many later generations. Thus, almost all risk should be passed forward to future generations. This conclusion remains even if we introduce an autocorrelation structure to the error terms, as long as no shock leaves permanent aftereffects. Similarly, we can allow individuals to consume throughout their life, have lotteries which occur at any point during their life, and have any type of risk-averse utility function, and still argue that idiosyncratic risks ought to be pooled. Allowing for population growth would only increase the incentive to share risk with the future. ${ }^{9}$

\section{Risk sharing between generations: Complicating factors}

The above model did not attempt to examine the mechanism by which random transfers are made between generations. The only available means to transfer wealth across time, however, is through changes in the capital stock. In the above argument, these fluctuations in the capital stock had no effect on rates of return, and we did not impose a non-negativity constraint on the capital stock. In addition, we implausibly assumed that the variance of the random fluctuation in income had no relation to the size of the existing capital stock.

In this section we try to shed some light on how these complications affect the nature of the efficient risk-sharing scheme. A general analysis of efficient policies would maximize the utility of some generation $t$, using any feasible government policy, subject to the constraints that each other generation receive at least some guaranteed level of utility. The analysis of this sort of model, which is closely related to the analyses of stochastic growth models in Merton (1975) or Brock and Mirman (1972), is sufficiently complicated, however, that it provides little or no understanding concerning what factors have important effects on the efficient degree of risk sharing.

Our objective instead is to show in a much simpler setting which factors are important in limiting the efficient degree of risk sharing. We simplify the analysis first by assuming that feasible policies are restricted to those which allocate a proportional amount, $a_{i}$, of each lottery to the generation born $i$

\footnotetext{
${ }^{8}$ Note that this argument does not require any specification about who holds the debt; it could easily be outside debt, held by foreigners.

${ }^{9} \mathrm{Abel}$ (1987), in response to our paper, considers intergenerational risk sharing with population growth.
} 
periods later, for $i=0, \ldots, n$, where $a_{i}$ is not allowed to vary over time, as a function of the state of the economy, or as a function of the outcome of the lottery. By relaxing these restrictions on feasible policies, a further Pareto improvement would in principle be possible.

The second simplifying assumption we make is that the objective of the government is to maximize the expected utility of the steady-state generations, expected as of the date when the policy is enacted, given that the earlier generations receive ex ante at least as much utility as they would have received with no intervention. By steady-state generations we mean those generations who share in $n-1$ past lotteries in addition to keeping some share of their own lottery. If a policy raises steady-state utility, subject to the constraints, then it is a Pareto improvement. However, such a policy will certainly not be the only policy leading to a Pareto improvement.

Our definition of a Pareto improvement in the context of differential information may be somewhat controversial. We have adopted the view that a Pareto improvement means that each generation is expected to be better off given the information available at the time of enactment of the policy. An alternative definition of Pareto improvement, examined in Peled (1982), requires that each generation have a higher expected utility at birth, conditional on the information available at that time. In the context of intergenerational redistribution, this would require that each generation have higher expected utility given the payments it owes to the previous generation. Peled shows that, under his definition, a competitive equilibrium is Pareto efficient, and thus no government intervention is warranted.

In contrast, our definition of Pareto improvement requires only that each generation gains by the policy change in the eyes of the decision-maker, evaluated using the information available at the time the policy is enacted. Under this definition, government intervention to facilitate risk sharing is appropriate.

Using the model of the economy of section 2, a steady-state generation, born in period $t$, would end up with consumption equal to $w+\sum_{i=0}^{n-1} a_{i} e_{t-i}$ and expected utility of $U(w)-V\left(s \sum a_{i}^{2}\right)$. The policy which maximizes steadystatc utility is thereforc simply $a_{i}=1 / n$ for all $i$. Under this policy, earlier generations are even better off, so this policy is a Pareto improvement. In fact, this policy is precisely the equal sharing policy examined previously in section 2. In the following sections, we examine how the chosen policy changes as we change assumptions.

\subsection{Role of the capital stock in transferring risk to later generations}

When a contingent dollar is transferred from generation $t$ to generation $t+1$ in the above story, the physical process is that a contingent dollar is 
added to the capital stock in period $t+1$. However, this simple story ignores a number of implications of using capital to transmit risk.

To begin with, capital is used in production and earns a marginal product. As a result, when some contingent dollar is transferred from generation $t$ to generation $t+1$, generation $t+1$ receives this contingent dollar plus the marginal product that it has produced while embodied in capital. Therefore generation $t+1$ receives a larger lottery than generation $t$ gives up, changing the desired degree of risk sharing.

In addition, the physical capital stock must certainly be non-negative. But when the policy proposed in section 2 is used to share risk among $n$ generations, the capital stock saved by a steady-state generation would equal $w+\sum_{j=1}^{n-1}((n-j) / n) e_{t-j}$. There is nothing in the model which assures that this capital stock is positive. Moreover, as $n$ gets larger, the stochastic process for the capital stock behaves like a random walk from one generation to the next, and a random walk has probability one of hitting any boundary (e.g. a requirement that the capital stock be non-negative) in finite time. Our model therefore does not guarantee that net assets remain positive.

The prime force keeping the capital stock positive is presumably the large marginal product of capital when the capital stock is small. Assume, for example, that the income earned by capital equals $f\left(k_{t}\right)+e_{t}$, where $f^{\prime}>0$, so that capital has a positive marginal product, and where $f(\cdot)$ satisfies the Inada conditions so that the optimal capital stock will always be positive.

In this setting, it is easy to show that at least some risk sharing remains worthwhile. Consider, for example, a two generation tax-transfer scheme, whereby consumption of generation $t$ equals $w+a e_{t-1}+f\left(w+a e_{t-1}\right)+$ $(1-a) e_{t}$. Given this transfer policy, the utility of a generation in steady-state can be expressed as:

$$
\begin{aligned}
& U\left[w+E f\left(w+a e_{t-1}\right)\right] \\
& \quad-V\left[(1-a)^{2} s+a^{2} s+\operatorname{var}\left(f\left(w+a e_{t-1}\right)\right)+2 E a e_{t-1} f\left(w+a e_{t-1}\right)\right] .
\end{aligned}
$$

The first derivative of utility with respect to $a$ equals:

$$
U^{\prime} \frac{\partial E f}{\partial a}-2 V^{\prime}\left[\operatorname{cov}\left(f, f^{\prime} e_{t-1}\right)-(1-2 a) s+E e_{t-1} f+a E e_{t-1}^{2} f^{\prime}\right]
$$

Evaluated at $a=0$, this derivative simplifies to $2 s V^{\prime}$, which is clearly positive. Therefore a small increase in risk sharing must raise steady-state utility. Since the first generation clearly gains by sharing any fraction of its own lottery with the next generation, this policy is a Pareto improvement.

However, eq. (1) implies that the resulting degree of risk sharing is less than that found in the simpler model of section 2 . If, in eq. (1), all terms but 
the third equal zero, then the equation implies that the chosen value of $a$ equals $1 / 2$, as before. However, at least as long as the distribution of $e_{t-1}$ is symmetric around zero, we demonstrate in the appendix that each of these extra terms is negative, implying that the gain from increasing risk sharing from any starting point is smaller. When risk sharing is increased, both mean income is lower, and the variance of income is higher, because of the effects of risk sharing on capital income. Therefore, in general, the optimal value of $a$ is less than one-half.

Consider, for example, the special case where $f\left(k_{t-1}\right)=r k_{t-1}$. Using this expression for the production function, we can solve eq. (1) for the optimal value of $a$. We find that $a^{*}=1 /\left[1+(1+r)^{2}\right]$. Due to the positive marginal product of capital, we find that the optimal value of $a$ is less than one-half.

\subsection{Compounding of lotteries}

So far we have assumed that the size of the lottery, $e_{t}$, is not tied to the size of the capital stock. However, if the return to capital is stochastic, then there is an additional cost of transferring a contingent dollar to the next generation - by the time the next gencration reccives it, this contingent dollar has grown in variability.

For example, assume that if the capital stock entering period $t$ is $k_{t-1}$, then output in period $t$ equals $k_{t-1}\left(1+e_{t-1}\right)$. If generation $t$ is still alloted the share $a_{i}$ of the lottery occurring $i$ periods earlier, then its consumption in period $t+1$ would equal $w\left(1+a_{0} e_{1}\right)+\sum_{i=1}^{n-1} w e_{t-i} a_{i}\left[\prod_{i=0}^{i-1}\left(1+e_{t-j}\right)\right]$. If all the lotteries continue to be independent, then steady-state utility equals:

$$
U(w)-V\left(s \sum_{i=0}^{n-1} a_{i}^{2}(1+s)^{i}\right) .
$$

Maximizing steady-state utility with respect to $a_{i}$, subject to the constraint that $\sum_{i} a_{i}=1$, we find that:

$$
a_{i}^{*}=\frac{(1+s)^{-i}}{\sum_{j=0}^{n-1}(1+s)^{-j}} .
$$

Under this policy, earlier generations again gain even more, since they share in fewer past lotteries, implying that this policy is a Pareto improvement. In the limit, as $n$ increases, $a_{i}^{*}=s /(1+s)^{1+i}$. With the chosen policy, each generation bears the share $s /(1+s)$ of its own lottery and a share in each past lottery which diminishes in size the more distant the lottery. When risk is passed to a later generation, it grows in variability due to the random return 
it earns each period. As a result, it is more expensive than in our base case to pass risk on to later generations, and less ought to be done.

\section{Time consistency of the policy}

In analyzing the government policy so far, we have assumed that what is optimal ex ante will in fact be done ex post. However, at each future date, both generations know the outcome of past lotteries. Even though every generation gains ex ante under the proposed risk-sharing policy, some generations will certainly lose ex post, for someone has to absorb whatever losses have occurred. These generations that lose ex post may well be able to repeal the risk-sharing program and so avoid the obligations they would otherwise have faced. Any risk-sharing program must therefore take into account this possibility of future default in its initial design.

Is it possible to design a time-consistent risk-sharing plan, which will not be repealed regardless of the realizations of the random variable $e_{t}$ ? In this section we show that while a requirement of time consistency certainly imposes constraints on the design of a risk-sharing plan, a plausible case can be made that government debt, and particularly a transfer program that always involves transfers from young to old, such as existing Social Security programs, would be time-consistent.

Any analysis of time consistency must rest heavily on the assumptions made about the political decision-making process. We begin by assuming that political decisions are determined by the median voter, and that the median voter is a member of the younger generation. In addition, we assume that voters can repeal an existing risk-sharing policy, but cannot otherwise change its design. Without this assumption, each generation would try to obtain non-stochastic transfers at the expense of other generations. Finally, we assume, for simplicity, that risks are shared between only two generations and that there are a discrete number of possible outcomes of the random variable $e_{t}$.

It quickly follows, by a simple application of stochastic dominance, that any risk-sharing policy would eventually be repealed. An intergenerational transfer plan is simply a function, $p\left(e_{t}\right)$, that describes the transfer from generation $t+1$ to generation $t$ as a function of the outcome of the random variable $e_{t}$. The constraint that the younger generation finds in its interest to participate in the risk-sharing scheme given the outcome $e_{t}$ can be written as:

$$
E_{t} u\left(w_{t+1}-p\left(e_{t}\right)+p\left(\tilde{e}_{t+1}\right)+\tilde{e}_{t+1}\right) \geqq E_{t} u\left(w_{t+1}+\tilde{e}_{t+1}\right) .
$$

In this expression we have used tildes to emphasize the fact that generation $t$, when it is young, does not yet know the outcome of its own lottery, $\tilde{e}_{t+1}$, but does know the outcome of the previous generation's lottery, $e_{t}$. In order to 
have no incentive for default regardless of the outcome of generation $t$ 's lottery, this constraint must hold for all values of $e_{t}$.

But we claim that these constraints can only be satisfied by the trivial transfer scheme in which $p\left(e_{t}\right)$ is a constant, and so provides no risk sharing. Assume, to the contrary, that $p(\cdot)$ is not constant, and let $p_{\max }$ be the maximum value it takes on. Then in order to satisfy the above constraint for $p\left(e_{t}\right)=p_{\max }$ we must have:

$$
E u\left(w_{t+1}-p_{\max }+p\left(\tilde{e}_{t+1}\right)+\tilde{e}_{t+1}\right) \geqq E u\left(w_{t+1}+\tilde{e}_{t+1}\right)
$$

But since $p_{\max } \geqq p\left(\tilde{e}_{t+1}\right)$ for all realizations of $\tilde{e}_{t+1}$, this constraint can be satisfied only if $p_{\max } \equiv p\left(\tilde{e}_{t+1}\right)$, which implies that the only feasible transfer policy is the trivial policy. ${ }^{10}$

This stark conclusion implies that an intergenerational risk-sharing scheme is infeasible, due to problems with time consistency. ${ }^{11}$ However, the argument is not robust to a number of modifications of the model. For example, if the young generation must pay a sizable enough penalty if it repeals the policy, then it may no longer find it in its interest to do so. If the transfer to the old generation took the form of debt-financed transfers in the past, then repeal amounts to some form of repudiation of the existing government debt. But, explicit default would involve substantial financial disruption, and could easily not be worth the cost. Implicit default through unexpected inflation carries with it all the various costs of inflation, which could again outweigh the benefits of reducing the size of the transfer to the previous generation. ${ }^{12}$ If these costs of full default, denoted by $C$, are large enough so that $E u\left(w_{t+1}-p_{\max }+p\left(\tilde{e}_{t+1}\right)+\tilde{e}_{t+1}\right) \geqq E u\left(w_{t+1}+\tilde{e}_{t+1}-C\right)$, then default would never occur. Therefore, use of debt finance to share risk between generations could well prove to be time-consistent.

The fact that the young generation will always desire default in some circumstances does not immediately imply that the government will agree to such a default. After all, the old definitely benefit from a transfer, and how the political system balances the benefits and costs to the two generations

\footnotetext{
${ }^{10}$ In this argument, we have implicitly assumed that the rate of population growth (plus the rate of technical exchange) just equals the non-stochastic rate of return to capital, so that a contingent dollar allocated to the next generation results in that generation receiving a contingent dollar of extra consumption. The argument breaks down if the rate of population growth exceeds the marginal product of capital, for then the maximum possible payment from the next generation is greater than $p_{\max }$, so that repeal is not stochastically dominant. Abel (1987) presents a numerical example showing that intergenerational risk sharing can be timeconsistent in this case. But in this situation the economy is beyond the golden rule level of the capital stock implying other possible ways to increase everyone's utility.

${ }^{11}$ We suspect that this phenomenon is rather general and will arise in other models of intertemporal lending. For example, Rogoff and Bulow (1988) have independently derived a similar result in the context of international debt.

${ }^{12}$ For a discussion of possible social costs of inflation, see, for example, Okun (1975).
} 
will determine the outcome of the generational conflict. One standard model of the political process is the median voter model. With this specification, everything depends on whether the median voter is young or old. As an empirical matter, the old are more likely to vote than the young, and the median age of voters is well above the median age of those eighteen years old and over. But if the median voter is old, then a risk-sharing plan would be time-consistent as long as it always involves a positive transfer from young to old, with only the size and not the sign of the transfer depending on the outcome of $e_{t}$. But this is just the form of the U.S. Social Security program, which has proven to be remarkably stable politically. Under this type of scheme the first generation clearly gains, since it receives benefits from the next generation without paying any to the previous generation. Therefore, there would be a strong incentive to enact this program, and as long as the median voter remains old it would be time-consistent.

Even if the median voter were young, our assumption that decisions depend solely on the preferences of the median voter is far too simple a model of political decision making. Under the median voter model, the strengths of individual preferences do not matter at all, only their sign. But individuals have a variety of ways of making the strengths of their preferences known. For one, they can contribute time and resources to lobby for their position, if they have enough at stake. In addition, they can engage in logrolling by simultaneously enacting another piece of legislation that more than compensates those who lose under the initial bill. One simple way to generalize the median voter model, without making this process explicit, is simply to assume that the political decision depends on the magnitude of the dollar benefits accruing to each generation.

Let us reconsider our argument for default under this model of political decision making. Suppose, as before, that the state occurs which involves the largest transfer from the young to the old, $p_{\max }$. Then if default occurs, the old lose $p_{\max }$ and the young gain $p_{\max }$ this period. But the young also lose the expected utility of the transfer that they would receive in period $t+1$ if the program were to remain in effect. If this is positive, as it must be under a Social Security type transfer scheme, then the dollar loss from default to the old generation is greater than the expected present value of the gains from default to the young generation. If the political decision depends on the magnitudes of the gains versus the losses, the intergenerational risk-sharing scheme could well be politically time-consistent, even though the young generation would, by itself, prefer to default.

\section{Comparison with alternative explanations for cyclical debt issues}

In this paper we have argued that one motivation for debt finance of wars and recessions may be to share current random outcomes with future 
generations. Of course, other explanations for the cyclical nature of debt issues, and for the existence of the Social Security Program, can be proposed. While it would be difficult to measure the relative importance of each of the various possible explanations for debt issues, some discussion is in order.

The obvious alternative explanation for cyclical debt policy is simply the government's active pursuit of a Keynesian stabilization policy. Whatever the current views among economists about the efficacy of a stabilization policy, it is undoubtedly the case that in the past governments have attempted to use fiscal policy to stabilize the economy. However, in financing a war, such as the Second World War, Keynesian stabilization policy would suggest the use of tax finance in order to suppress private demand to free resources for the military, whereas the data indicate that the Second World War was financed primarily with debt. ${ }^{13}$ This debt has been paid off only gradually during the post-war period, consistent with our story that it is being passed forward to later generations. This extended pay-back period cannot be explained by a Keynesian stabilization policy, though perhaps is not inconsistent with it either. It is also difficult to explain the introduction of Social Security during the Great Depression on stabilization grounds, particularly given that bencfits did not commence for several years. If private demand depends on current income, perhaps due to liquidity constraints, then payroll taxes lower current demand while promises of future income cannot increase it. Yet the introduction of Social Security, with clear net gains to the initial Depression generations, is easily explained by our risksharing story.

An alternative explanation for cyclical debt issues is found in Barro (1979). He argues that the efficiency cost of raising a given amount of government revenue through taxes is increased when the marginal tax rate varies over time. Intuitively, the excess burden of a tax is proportional to the square of the tax rate, so that the excess burden increases as the variability of tax rates increases, holding the average tax rate fixed. Therefore the government, in order to minimize the efficiency cost of collecting a given average tax revenue, will wish to maintain constant marginal tax rates over time, and absorb fluctuating annual tax revenue through fluctuations in net debt issues.

Given the presence of a progressive income tax, in order to have a constant marginal tax rate in the face of fluctuations in annual income, two approaches can be used. The first is income averaging in the tax law. While long advocated by tax economists, the degree of income averaging allowed under the existing U.S. personal income tax law is extremely limited, suggesting that this is not an important objective of the tax. ${ }^{14}$ In fact,

\footnotetext{
${ }^{13}$ According to the figures in the Economic Report of the President, the increase in the Federal debt in 1942 was 1.49 times the size of Federal Government revenues. The equivalent figures in 1943 and 1944 were 2.64 and 1.40 , respectively.

${ }^{14} \mathrm{See}$, for example, Vickrey (1947).
} 
income averaging was repealed in the United States in 1986. Given the lack of importance of income averaging in the law, marginal tax rates will fall when income falls because of the progressivity of the tax schedule. Therefore, by Barro's argument, a fall in income should be accompanied by a tax surcharge to push individuals back into their original tax bracket. Pressure for tax surcharges during recessions has not been the rule during the postwar period, so it seems difficult to accept Barro's explanation for historical patterns of debt issue. In fact, Barro's cmpirical cstimates show that tax revenues have fluctuated much more as income has fluctuated than his theory would forecast. He attributes this to the use of a stabilization policy. To a degree, these excess fluctuations might also be explained by intergenerational risk sharing.

Similarly, there have been many alternative rationalizations proposed for the enactment of the Social Security Program. The program provides annuity insurance which may be expensive to buy individually for adverse selection reasons, it provides an indexed income stream which may be hard to duplicate in the securities market, and it provides benefit levels that are contingent upon many random events in an individual's life. However, any of these explanations cannot explain the timing of the introduction of Social Security, nor can they explain the large transfers received by the initial cohorts of retirees, who for the most part were old enough to have suffered substantial losses of labor income and capital during the Great Depression and the Second World War.

\section{The family as an alternative risk-sharing institution}

Why cannot the family provide the same type of risk sharing between generations of the family that the above government policies would provide? If parents are altruistic and would always wish to leave a positive bequest, regardless of events, then they could easily provide the same risk sharing. The above analysis in effect characterizes the risk-sharing policy they would follow. In general, however, the family would face a number of difficulties not faced by the government.

If parents do expect to be able to share their lotteries with future generations within their family, then they would wish to maintain close to their normal consumption level even during a very unfavorable event, e.g. a depression. However, they may not at that point have the financial assets to fund this consumption level. Under the government risk-sharing policy, the government would issue debt and use it to finance transfer payments. Under the analogous family policy, the parents would try to borrow funds to finance their consumption. However, they would lack collateral for the loan, and could not legally commit their children to pay it back. In contrast, the 
government would not need explicit collateral and can legally bind future generations whenever it issues debt.

As we saw in the previous section, a political coalition might well develop under certain circumstances to repeal a government risk-sharing policy. Within a family risk-sharing policy, each generation would face similar incentives to 'repeal' the policy. However, within the family, the paying generation could repeal the policy on its own regardless of the preferences of the receiving generation. Repealing a family risk-sharing policy is much easier than repealing a government policy.

When would a generation within the family wish to 'repeal' the risksharing policy? When considering the preferences of a generation under a government risk-sharing policy, we assumed that there was a clear link between its willingness to participate in the policy when it is young and its likelihood of participating in the policy when it is old. In particular, we assumed that if the policy were repealed now, it would not exist during the next period. Within the family, however, there is no contractual link between transfers now and transfers next period. Children may well hope that their children will help them out, independently of whether they help their parents out. Without this link hetween transfers now and transfers next period, every generation would face an incentive to renege. Altruism may overcome this, but without sufficient altruism the family risk-sharing policy is likely to break down.

\section{Conclusions}

In this paper we have argued that in designing government debt and taxtransfer policies, it is important to consider their implications for the allocation of risk betwecn gencrations. Therc is no rcason to presume that the market or the family can allocate risk efficiently to future generations, implying that stochastic government policies have the potential to create first-order welfare improvements. The model provides a non-Keynesian justification for the debt-finance of wars and recessions, as well as an added rationale for Social Security type tax-transfer schemes which aid unlucky generations, e.g. the Depression generation, at the expense of luckier generations.

It is premature, though, at this point to draw any conclusions concerning the degree to which government debt or tax-transfer policy ought to be modified in light of risk-sharing considerations. Given the theoretical difficulties of characterizing the optimal policy in more general settings, the answer to this question must await further analysis.

\section{Appendix}

To see that the extra terms in eq. (1) are negative, consider each in turn. 
The first term measures the drop in expected capital income when more risk is shared. Since the production function is concave, adding random fluctuations to the capital stock causes expected capital income to fall. The last term inside the bracket is clearly positive since each element in the product is positive, so that this term also reduces the measure of the utility gain from increasing the degree of risk sharing.

In order to show that the other two extra terms also reduce the measure of the gain from further risk sharing, the following lemma is helpful:

Lemma 1. Let $x(e)$ be some function of a random variable $e$. If the distribution of the random variable $e$ is symmetric around zero, and if $x(e)+x(-e)<(>) 0$ for all values of $e$, then $E(x(e))<(>) 0$.

Proof. If $\phi(e)$ represents the density function of $e$, then, given that the density function of $e$ is symmetric, we know that $E(x(e))=$ $\int_{0}^{\infty}(x(e)+x(-e)) \phi(e) \mathrm{d} e$. The result follows trivially.

To sign the next to last term inside the brackets in eq. (4), let $x(e)=e_{t-1} f$. Then $x(e)+x(-e)=e_{t-1}\left(f\left(w+a e_{t-1}\right)-f\left(w-a e_{t-1}\right)\right)$. Since capital income is an increasing function of the capital stock, this expression is positive. The lemma then implies that $E\left(e_{t-1} f\right)>0$.

To see that the first term inside the brackets is also positive, the following lemma is helpful:

Lemma 2. Let $F(e)$ and $G(e)$ be two continuous functions of the random variable $e$ with zero means. Let $e^{*}$ denote the minimum value of $e$ at which both $F$ and $G$ are non-negative. Then $E(F G)>0$ as long as $(I) \operatorname{sign}(F(e)-$ $\left.F\left(e^{*}\right)\right)=\operatorname{sign}\left(e-e^{*}\right)$ and $(2) \operatorname{sign}\left(G(e)-G\left(e^{*}\right)\right)=\operatorname{sign}\left(e-e^{*}\right)$.

Proof. Either $F\left(e^{*}\right)$ or $G\left(e^{*}\right)$ must equal zero; assume without loss of generality that it is $G\left(e^{*}\right)$. Let $\phi(e)$ denote the density function of $e$. Then, it follows directly from conditions (1) and (2) that $E(F G) \equiv \int F G \phi=$ $F\left(e^{*}\right) \int G \phi+\int\left(F-F\left(e^{*}\right)\right) G \phi \geqq F\left(e^{*}\right) \int G \phi$ by conditions (1) and (2). But $\int G \phi=0$ since the random variable has a zero mean, so $E(F G)>0$.

In applying this lemma, let $F=f-E(f)$ and $G=f^{\prime} e_{t-1}-E\left(f^{\prime} e_{t-1}\right)$. Since $f$ is an increasing function of $e_{t-1}$, condition (1) is satisfied for any value of $e_{t-1}^{*}$. In contrast $G\left(e_{t-1}\right)$ is necessarily increasing in $e_{t-1}$ only for $e_{t-1} \leqq 0$. All we can say beyond that is $G\left(e_{t-1}\right)>G(0)$ for $e_{t-1}>0$. However, if $e_{t-1}^{*}<0$, condition (2) would still be satisfied. By the concavity of $f$, we know that $E(f)<f\left(E\left(e_{t-1}\right)\right)=f(0)$. In addition, an immediate application of Lemma 1 shows that $E\left(f^{\prime} e_{t-1}\right)<0$, implying that $G(0)>0$. Therefore $e_{t-1}^{*}<0$, and 
Lemma 2 implies that the first term inside the brackets in eq. (4) also lowers the gain from further risk sharing.

\section{References}

Abel, Andrew, 1987, The implications of insurance for the efficacy of fiscal policy (Wharton School of the University of Pennsylvania, Philadelphia, PA).

Aizenman, Joshua, 1981, The use of the balance of payments as a shock absorber in fixed rate and managed float systems, Journal of International Economics 11, 479-486.

Azariadis, C., 1975, Implicit contracts and underemployment equilibria. Journal of Political Economy 83, 1183-1202.

Baily, M.N., 1974, Wages and employment under uncertain demand, Review of Economic Studies 41, 37-50.

Barro, Robert, 1979, On the determination of the public debt, Journal of Political Economy 87 , 940-971.

Battacharya, S., 1982, Aspects of monetary and banking theory and moral hazard, Journal of Finance 37, 371-384.

Brock, W. and L. Mirman, 1972, The stochastic modified golden rule in a one sector model of economic growth with uncertain technology, Journal of Economic Theory 4, 79-513.

Buchanan, J., 1976, Taxation in fiscal exchange, Journal of Public Economics 6, 17-30

Diamond, P., 1965, National debt in a neoclassical growth model, American Economic Review $41,1126-1150$

Eaton, J. and H. Rosen, 1980, Taxation, human capital and uncertainty. American Economic Review 70, 705-715.

Enders, W. and H.E. Lapan, 1982, Social security taxation and intergenerational risk sharing International Economic Review 23, 647-658.

Fischer, S., 1982, Welfare aspects of government issue of indexed bonds, NBER Working paper no. 874 .

Foley, D. and M. Hellwig, 1975, Asset management with trading uncertainty, Review of Economic Studies 42, 327-346.

Gordon, R., 1985, Taxation of corporate capital income: Tax revenues vs. tax distortions, Quarterly Journal of Economics 100, 1-27.

Green, J., 1977, Mitigating demographic risk through social insurance, NBER Working paper no. 215.

Laitner, J., 1981, The steady states of a stochastic decentralized growth model, Journal of Economic Theory 24, 377-392.

Merton, R.C., 1971, Optimal consumption and portfolio rules in a continuous-time model, Journal of Economic Theory 3, 373-413.

Merton, R.C., 1975, An asymptotic theory of growth under uncertainty, Review of Economic Studies 42, 375-393.

Merton, R.C., 1984, On the role of social security as a means for efficient risk-bearing in an economy where human capital is not tradeable, in: Zvi Bodie and John Shoven, eds., Financial aspects of the United States pension system (University of Chicago Press, Chicago, IL).

Okun, A.M., 1975, Inflation: Its mechanics and welfare costs, Brooking Papers on Economic Activity 2, 351-402.

Peled, D., 1982, Informational diversity over time and the optimality of monetary equilibria, Journal of Economic Theory 28, 255-274.

Rogoff, K. and J. Bulow, 1988, Sovereign debt: Is to forgive to forget?, American Economic Review, forthcoming.

Smith, A., 1982, Intergenerational transfers as social insurance, Journal of Public Economics 19, 97-106. 
Stiglitz, J., 1983, On the relevance or irrelevance of public financial policy: Indexation, price rigidities, and optimal monetary policies, in: Rudiger Dornbusch and Mario Henrique Simonsen, eds., Inflation, debt and indexation (MIT Prcss, Cambridge, MA).

Varian, H., 1980, Redistributive taxation as social insurance, Journal of Public Economics 14, 49-68.

Vickrey, William, 1947, Agenda for progressive taxation (The Ronald Press Company, New York).

Wellisz, Z. and J.D. Wilson, 1984, A theory of tariff formation, unpublished. 